\title{
Pregravid contraceptive use and fecundability: prospective cohort study
}

\author{
Jennifer J Yland, ${ }^{1}$ Kathryn A Bresnick, ${ }^{1}$ Elizabeth E Hatch, ${ }^{1}$ Amelia K Wesselink, ${ }^{1}$ \\ Ellen M Mikkelsen, ${ }^{2}$ Kenneth J Rothman, ${ }^{1,3}$ Henrik T Sørensen, ${ }^{1,2}$ Krista F Huybrechts, ${ }^{4}$ \\ Lauren A Wise ${ }^{1}$
}

${ }^{1}$ Department of Epidemiology,

Boston University School of

Public Health, 715 Albany Street,

Boston, MA 02118 USA

${ }^{2}$ Department of Clinical

Epidemiology, Aarhus University

Hospital, Aarhus, Denmark

${ }^{3}$ RTI Health Solutions, Research

Triangle Park, NC, USA

${ }^{4}$ Division of

Pharmacoepidemiology

and Pharmacoeconomics,

Department of Medicine,

Brigham and Women's Hospital,

Harvard Medical School, Boston,

MA, USA

Correspondence to: I I Yland

yland@bu.edu

(or @jennifer_yland on Twitter

ORCID 0000-0001-7870-8971)

Additional material is published

online only. To view please visit

the journal online.

Cite this as: BMJ 2020;371:m3966 http://dx.doi.org/10.1136/bmj.m3966

Accepted: 18 September 2020

\section{ABSTRACT}

OBJECTIVE

To evaluate the association between pregravid use of a variety of contraceptive methods and subsequent fecundability.

\section{DESIGN}

Prospective cohort study.

SETTING

Denmark and North America, 2007-19.

PARTICIPANTS

17954 women who had tried to conceive for up

to six menstrual cycles at study entry. At baseline, participants reported their contraceptive histories, and personal, medical, and lifestyle characteristics.

\section{MAIN OUTCOME MEASURES}

Pregnancy, determined by bimonthly follow-up questionnaires for up to 12 months.

\section{RESULTS}

Approximately $38 \%(n=6735)$ of participants had recently used oral contraceptives, $13 \%(n=2398)$ had used long acting reversible contraceptive methods, and 31\% $(n=5497)$ had used barrier methods. Women who had recently stopped using oral contraceptives, the contraceptive ring, and some long acting reversible contraceptive methods experienced short term delays in return of fertility compared with users of barrier methods. Use of injectable contraceptives was associated with decreased fecundability compared with use of barrier methods (fecundability ratio $0.65 ; 95 \%$ confidence interval 0.47 to 0.89 ). Users of injectable contraceptives had the longest delay in return of normal fertility (five to eight menstrual cycles), followed by users of patch contraceptives (four cycles), users of oral

\section{WHAT IS ALREADY KNOWN ON THIS TOPIC}

Use of long acting reversible contraceptives has become increasingly common but epidemiologic studies of their effect on return of fertility have been small and inconsistent

Research on use of contraceptives and fertility has focused mainly on the effects of oral contraceptives, with most studies showing short delays in the return of fertility after stopping oral contraceptives

\section{WHAT THIS STUDY ADDS}

This study quantified the delay in return of fertility after use of a variety of contraceptive methods

On average, users of injectable contraceptives had the longest delay in return of normal fertility (five to eight menstrual cycles) and users of hormonal and copper intrauterine devices and implant contraceptives had the shortest delays (two menstrual cycles) and ring contraceptives (three cycles), and users of hormonal and copper intrauterine devices and implant contraceptives (two cycles). Lifetime length of use of hormonal contraceptive methods was not associated with fecundability.

\section{CONCLUSIONS}

Use of some hormonal contraceptive methods was associated with delays in return of fertility, with injectable contraceptives showing the longest delay. The findings indicated little or no lasting effect of long term use of these methods on fecundability.

\section{Introduction}

Worldwide, about $22 \%$ of women of reproductive age used hormonal contraception in 2019. ${ }^{1}$ In the United States, $35 \%$ of women of reproductive age used hormonal contraception in 2015-17. ${ }^{2}$ Although male condoms and oral contraceptives remain the most commonly used methods in North America and Europe, ${ }^{1}$ long acting reversible contraceptive methods have become increasingly popular. ${ }^{2}$ Long acting reversible contraceptive methods include intrauterine devices, implants, and injectable contraceptives. ${ }^{3}$ In the US, $2 \%$ of women aged 25-34 used long acting reversible contraceptive methods in 1995 compared with $13 \%$ of similarly aged women in $2015-17^{23}$ In Europe, $9 \%$ of women of reproductive age reported that they used long acting reversible contraceptive methods in 2019. ${ }^{1}$

Most research on the use of contraceptives and fertility has focused on the effect of oral contraceptives on fecundability; the average probability of pregnancy during one menstrual cycle for a couple engaging in regular intercourse without contraception. Several studies reported delays of about three months in return of fertility after stopping oral contraceptives. ${ }^{4-6}$ In some ${ }^{57}$ but not all studies, ${ }^{4}$ women who used oral contraceptives for long periods had greater fecundability than women who used oral contraceptives for shorter periods. Less is known about the association between the use of other methods of contraception and fertility, however. Recent use of intrauterine devices (copper and hormonal methods combined) was associated with a slightly longer time to conception than use of barrier methods. ${ }^{68}$ The results are conflicting, ${ }^{49}$ however, and could be confounded by parity or underlying fecundity because previous indicators of fertility could affect the choice of contraceptive and the probability of conception in the future. One study indicated that recent use of injectable contraceptives might be associated with delayed conception. ${ }^{4}$ Most studies examining less common contraceptive methods 
have been small ${ }^{49}$ or retrospective in design, with a risk of recall bias. ${ }^{6} 8$ Given the increasing popularity of long acting reversible contraceptive methods and other alternatives to oral contraceptives, more research into their short and long term effects on fertility is needed.

This investigation was designed to examine fecundability in relation to recency and length of use of various hormonal and non-hormonal contraceptive methods, in three large preconception cohorts. The cohorts were from three prospective studies from North America and Denmark of women and men planning pregnancies.

\section{Methods}

\section{Study population}

We pooled data from three prospective cohort studies of participants planning pregnancies: Snart Gravid, a Danish study of women planning pregnancies, aged 1849 (2007-11); Snart Foraeldre, an extension of Snart Gravid that included male partners (2011-19); and Pregnancy Study Online (PRESTO), a North American study of women planning pregnancies, aged 21-45, and their male partners (2013-19). Recruitment for Snart Foraeldre and PRESTO is ongoing. Participants in all studies were recruited mainly by advertisements on social media and health related websites, such as Facebook and Netdoktor (www.netdoktor.dk, a well known Danish health related website) ${ }^{1011}$ For example, we used the following advertisement on Facebook to recruit participants for PRESTO: “Trying to conceive? Help scientists learn more about fertility. Enroll in an online research study.” The recruitment methods for the study have been described in detail elsewhere. ${ }^{10-12}$

Enrollment and primary data collection were done by email and through the study website. Eligible women were not pregnant, did not use contraceptives, were not receiving fertility treatment, and were trying to conceive. We excluded participants if they reported insufficient or implausible information on their menstrual cycle (Snart Gravid 5\%, Snart Foraeldre 8\%, PRESTO 2\%). We also excluded participants who had been trying to conceive for more than six menstrual cycles at study entry; excluding these participants reduced potential recall bias (that is, differential recall and reporting of exposures and covariates resulting from reduced fertility) and possible confounder misclassification, which might arise if women who had been trying to conceive for longer than six cycles changed their behavior as a result of not conceiving before entering the study. The proportions of women excluded because they had been trying to conceive for more than six cycles were 22\% in Snart Gravid, 25\% in Snart Foraeldre, and 20\% in PRESTO. Participants whose last method of contraception was not included in the present analysis (sterilization that was subsequently reversed, emergency contraception, and douching) were also excluded ( $<1 \%$ of participants). A total of 17954 participants were included in the pooled analyses: 4435 from the Snart Gravid study, 4768 from the Snart Foraeldre study, and 8751 from PRESTO (fig 1).
All questionnaires were completed online. At baseline, participants reported exposure and covariate information, including personal characteristics, lifestyle factors, and medical history. Follow-up questionnaires were done every two months for 12 months or until a pregnancy was reported, whichever came first. More than $80 \%$ of participants completed at least one follow-up questionnaire.All participants provided online informed consent.

\section{Assessment of contraceptive use}

At baseline, participants reported the contraceptive method used most recently before they tried to conceive ("Which birth control method did you use most recently?”). Categories included barrier methods (condoms, diaphragm, sponge, foam (Snart Gravid and Snart Foraeldre studies only), jellies, creams, and suppositories), oral contraceptives (progestin only and combined), hormonal intrauterine devices, copper intrauterine devices, patches, injectable contraceptives, vaginal rings, implants, and natural methods (withdrawal, avoiding sex when fertile, calendar methods, and monitoring cervical mucus or basal body temperature). Those who used hormonal methods recently were asked if they waited for a period of time after stopping hormonal contraception before trying to conceive ("Did you wait a few months after stopping hormonal contraception before trying to get pregnant?" If yes, "For how many months did you wait between stopping hormonal contraception and trying to get pregnant?").

To evaluate the potential effects of recent use of hormonal contraceptives, participants who reported waiting longer than one month before trying to conceive after stopping hormonal contraception were categorized as users of barrier or natural methods based on their questionnaire responses. Participants in the Snart Foraeldre and Snart Gravid studies selected only one "most recent" contraceptive method, but participants in PRESTO could select more than one method. Those who reported that they used both hormonal and barrier methods were categorized as users of the hormonal method, and those who reported that they used both barrier and natural methods were categorized as users of barrier methods. Participants who selected more than one hormonal method were categorized based on their reported ages when they stopped.

In PRESTO, participants reported the total number of hormonal contraceptive types they had used in their lifetime (oral contraceptives, rings, implants, injectable contraceptives, patches, hormonal intrauterine devices), the name of each method, and their ages when they started and stopped each method. Length of use (years) was calculated separately for each type of hormonal contraceptive. In the Snart Gravid and Snart Foraeldre studies, a detailed history of length of use was collected only for oral contraceptives.

\section{Assessment of fecundability}

We collected data on menstrual cycle dates and pregnancy status from the baseline and follow-up 


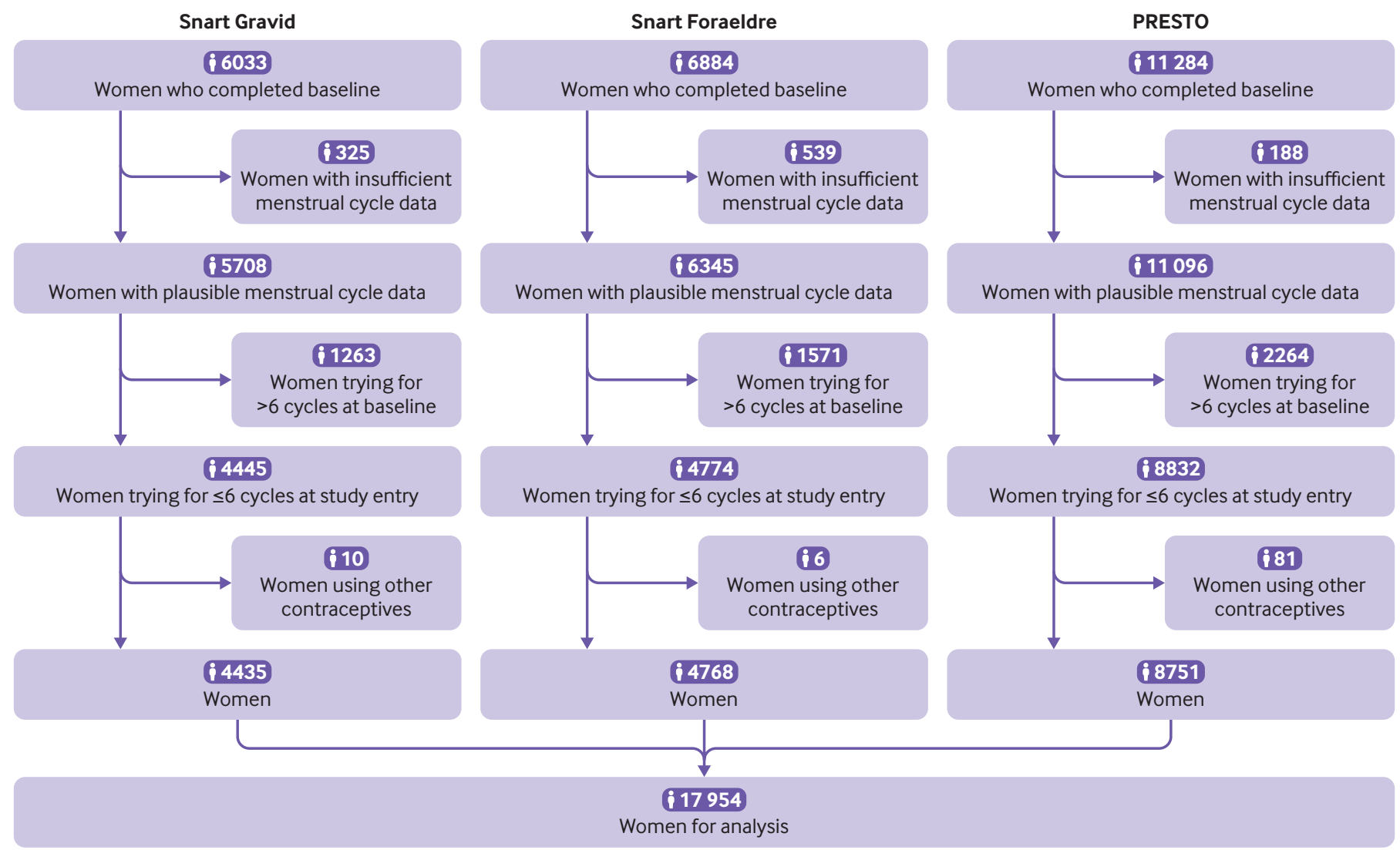

Fig 1 | Flowchart of enrolment and exclusions in the Snart Gravid, Snart Foraeldre, and PRESTO studies ( $\mathrm{n}=17954), 2007-19$

questionnaires. At baseline, participants reported the typical length of their menstrual cycle, the date of their last menstrual period, and the number of menstrual periods they had since they began trying to conceive. At each follow-up, women reported the date of their last menstrual period, whether they were pregnant, and whether they had started fertility treatment. In the PRESTO cohort, we also identified pregnancies in participants lost to followup by linking to birth registries, searching for baby gift registries and birth announcements online, and contacting the participants directly. We calculated pregnancy attempt time, rounded to the nearest whole cycle, as: (number of menstrual cycles participants had been trying to conceive at baseline)+[(date of last menstrual period from most recent follow-up questionnaire-date of baseline questionnaire)/cycle length]+1.

\section{Assessment of covariates}

At baseline, participants reported their age, height, weight, smoking history, education, household income, and frequency of intercourse; length of their relationship; whether they were trying to improve the chances of conception (eg, timing intercourse to their fertile period); length of the menstrual cycle and regularity; parity; history of infertility (previously tried to conceive for $\geq 12$ months); history of physician diagnosed endometriosis, uterine leiomyomata, polycystic ovarian syndrome, or type 2 diabetes; and whether they had ever been pregnant, the outcome of each pregnancy (miscarriage, induced abortion, livebirth), and whether the pregnancy had been planned. We calculated body mass index. In PRESTO, participants also reported their race and ethnicity at baseline. Education and household income were determined differently in the Danish and North American cohorts. To pool the data, we developed similar categories for each cohort by dichotomizing household income at \$50 000 (Danish Kr313 845; £38 250; €42 172) per year for the PRESTO cohort and Kr300000 (£6092; \$7963; €6717) per year for the Snart Foraeldre and Snart Gravid studies. Education was reported as years of education after compulsory schooling in the Snart Foraeldre and Snart Gravid studies and as overall years of schooling in PRESTO, and categorized accordingly.

\section{Statistical analysis}

Women contributed at risk cycles to the analysis from study entry until they reported a pregnancy, started fertility treatment, withdrew from the study, stopped trying to conceive, were lost to follow-up, or had 12 cycles of trying to conceive, whichever occurred first. We used life table methods to calculate the percentage of couples who conceived during six and 12 cycles of follow-up, accounting for censoring events. ${ }^{13}$ We used proportional probability regression models to calculate fecundability ratios with $95 \%$ confidence intervals. ${ }^{14}$ The fecundability ratio is a measure of the 
average probability of conception per cycle comparing users of a specific contraceptive method with a reference group. Proportional probability models adjust for cycle at risk, taking into account the average decline in fecundability as fertile couples conceive and are removed from the population at risk over time. ${ }^{14}$ We used the Andersen-Gill data structure to account for left truncation bias that might result from women entering the study after at least one cycle of trying to conceive. ${ }^{1516}$ For example, participants that entered the study after one cycle of trying to conceive, and conceived during the fifth cycle, contributed cycles two to five to the analysis.

We first examined the association between fecundability-the probability of conception per cycle-and use of oral contraceptives (combined and progestin only), hormonal intrauterine devices, copper intrauterine devices, rings, implants, patches, injectable contraceptives, and natural methods as the last method of contraception compared with barrier methods. We selected barrier methods as the reference group because: use of barrier methods would not be expected to cause changes in the vaginal environment or hormone concentrations, offering a well defined contrast with the use of hormonal methods; a large proportion of couples in our study used barrier methods; and we could compare our findings with previous studies that used the same reference category. We then examined fecundability after the use of hormonal intrauterine devices compared with copper intrauterine devices. To quantify delay in return of fertility for each method of contraception, we examined fecundability in each menstrual cycle when participants were trying to conceive. We considered the return of fertility to occur during the cycle in which fecundability for users of a specific method was not meaningfully lower than that for users of barrier methods (that is, adjusted fecundability ratio $>0.90$ ). Lastly, we examined the total length of use of each hormonal method. Total length of contraceptive use was divided into two year categories and compared with less than two years of use. In the Snart Foraeldre and Snart Gravid studies, this analysis was conducted only for oral contraceptives because of limited data on length of use.

Models were adjusted for potential confounders measured in the three studies and selected a priori based on the literature and a directed acyclic graph. Potential confounders included cohort (Snart Gravid, Snart Foraeldre, PRESTO); age (<25, 25-29, 30-34, $\geq 35)$; education $(\leq 12,13-15,16$, or $\geq 17$ years in North America or fundamental education, technical education or less than three years of higher education, three to four years of higher education, or greater than four years of higher education in Denmark); non-Hispanic white race and ethnicity (yes $v$ no); household income ( $<v \geq \$ 50000 /$ Kr300 000 annually); current smoker (yes $v$ no); body mass index $(<25,25$ 29 , $\geq 30$ ); baseline intercourse frequency (less than one, one to three, greater than three times a week); trying to improve the chances of conception (yes $v$ no); physician diagnosed diabetes (yes $v$ no); and lifetime length of use of hormonal contraceptives in months (oral contraceptives only in the Snart Gravid and Snart Foraeldre studies).

We also considered adjustment for possible indicators of underlying fertility because women with a previous pregnancy might be more likely to use a long acting reversible contraceptive method to avoid pregnancy if they believe it is more effective. Also, women with reproductive disorders associated with infertility might make contraceptive choices based on treatment recommendations (eg, use of oral contraceptives to treat polycystic ovarian syndrome ${ }^{17}$ ). In this analysis, we adjusted for history of unplanned pregnancy (yes $v$ no); history of induced abortion (yes $v$ no); history of infertility (yes $v$ no); menstrual cycle characteristics (irregular cycles, regular cycles of <26 days, regular cycles of 26-30 days, and regular cycles of $\geq 31$ days); parity (parous $v$ nulliparous); and physician diagnosed endometriosis (yes $v$ no), uterine leiomyomata (yes $v$ no), or polycystic ovarian syndrome (yes $v$ no). To examine effect measure modification, results for the most recent type of contraception were examined separately by cohort (Denmark $v$ North America), age ( $<30 v \geq 30)$, attempt time at study entry ( $<3$ v 3-6 menstrual cycles), body mass index ( $<30 v$ $\geq 30$ ), history of infertility (yes $v$ no), parity (parous $v$ nulliparous), and menstrual cycle regularity (regular $v$ irregular).

We conducted two sensitivity analyses to evaluate potential bias as a result of misclassification of exposure. We excluded women who stopped hormonal methods of contraception for one or more months before trying to conceive. These women could have switched from hormonal to barrier methods because of concerns that it would take time for the menstrual cycle to normalize after using hormonal contraceptives. Also, we separated progestin only from combined oral contraceptives to consider the potential extent of bias because of analyzing all oral contraceptives in one group. We conducted this analysis in the PRESTO cohort and evaluated the proportion of women who used progestin only oral contraceptives. We also examined the association between recent use of oral contraceptives and fecundability for progestin only and combined oral contraceptives separately.

In each cohort, we used PROC MI to impute missing exposure and covariate values, with over 100 variables in the imputation model to create five datasets. Last method of contraception was imputed for $0.7 \%$ of participants in PRESTO and for $0.5 \%$ of participants in the Snart Foraeldre and Snart Gravid studies. We also imputed missing outcome data for participants who did not complete any follow-up questionnaires (16\% in PRESTO and 13\% in Snart Gravid and Snart Foraeldre) to minimize potential selection bias. We assigned these participants one cycle of follow-up and imputed their pregnancy status (pregnant $v$ not pregnant) for that cycle. We used PROC MIANALYZE to combine coefficient and standard error estimates across imputed datasets. ${ }^{18}$ 


\section{Patient and public involvement}

No patients were involved in developing the research question, study design, or outcome measures, or in the implementation of this study.

\section{Results}

Overall, 17954 women contributed a total of 10729 pregnancies during 66759 menstrual cycles of observation to the analysis. With life table methods, about $56 \%$ and $77 \%$ of women conceived within six and 12 cycles of follow-up, respectively. After recategorizing participants who reported waiting longer than one month after stopping hormonal contraception, the most commonly reported last method of contraception was oral contraceptives $(37.5 \%)$, followed by barrier (30.6\%) and natural (15.4\%) methods (table 1). About $13.3 \%$ of women used long acting reversible contraceptive methods, and the most frequently used were intrauterine devices: $7.8 \%$ of women used the hormonal intrauterine device and $4.0 \%$ of women used the copper intrauterine device as their last method of contraception. The average number of pregnancy attempts before study entry was similar for all contraceptive methods (two menstrual cycles). Users of injectable contraceptives had a higher body mass index on average and were more likely to be current smokers, to report a history of infertility, to have irregular menstrual cycles, and to have type 2 diabetes than users of all other methods of contraception, but were less likely to report trying to improve their chances of conceiving. On average, users of implant, patch, and injectable contraceptives reported fewer years of education and lower household income than users of other methods. Users of intrauterine devices were more likely to be parous and to report a history of unplanned pregnancy than users of other contraceptive methods.

\section{Last method of contraception}

Use of injectable contraceptives as the last method of contraception was associated with decreased fecundability compared with use of barrier methods (fecundability ratio $0.65,95 \%$ confidence interval 0.47 to 0.89 ) after adjusting for personal factors, lifestyle characteristics, and medical history (table 2). This association remained after further adjustment for indicators of underlying fertility (fecundability ratio $0.65,95 \%$ confidence interval 0.47 to 0.89 ). Users of hormonal intrauterine devices had an increase in fecundability compared with users of barrier methods (fecundability ratio 1.23, 95\% confidence interval 1.15 to 1.31) and users of copper intrauterine devices (fecundability ratio 1.19, 95\% confidence interval 1.07 to 1.33). These associations were slightly reduced after further adjustment for indicators of underlying fertility. The fully adjusted fecundability ratio was 1.14 (95\% confidence interval 1.07 to 1.22 ) comparing users of hormonal intrauterine devices with users of barrier methods, and 1.18 (95\% confidence interval 1.05 to 1.33) comparing users of hormonal intrauterine devices with users of copper intrauterine devices. On average, use of oral contraceptives, copper intrauterine devices, rings, implants, patches, or natural methods as the last method of contraception was not meaningfully associated with fecundability compared with the use of barrier methods as the last method of contraception.

Figure 2 and table 3 show the cycle specific probability of conception and fecundability ratios, respectively, for recent users of different methods of contraception. Compared with users of barrier methods, we found varying delays in return of fertility for recent users of alternative methods. On average, users of injectable contraceptives had the longest delay in return of normal fertility (five to eight cycles), followed by users of patch contraceptives (four cycles), users of oral and ring contraceptives (three cycles), and users of hormonal and copper intrauterine devices and implant contraceptives (two cycles) (table 3). Our results were imprecise for these analyses, however. Because of the small numbers of women who used less common methods, we grouped cycles five to eight and nine to 12 for this analysis.

Overall, associations between last method of contraception and fecundability did not differ widely across cohorts (Denmark $v$ North America), age ( $<30$ $v \geq 30)$, or body mass index $(<30 v \geq 30)$ (table 4). The results varied by the number of menstrual cycles couples had been trying to conceive at study entry, however: relative to barrier methods, use of oral contraceptives, the patch, and injectable contraceptives was associated with decreased fecundability in women who had been trying to conceive for less than three cycles at study entry, but was associated with improved fecundability in women who had been trying to conceive for three to six cycles. This pattern is consistent with a short term delay in return of fertility. Results were similar across groups when we stratified by history of infertility, parity, and regularity of the menstrual cycle (table 4).

\section{Lifetime duration of use}

In the PRESTO cohort, no evidence was found of decreased fecundability with longer total lifetime use of oral contraceptives, rings, injectable contraceptives, hormonal intrauterine devices, implants, or patches (eTable 1). In Snart Gravid and Snart Foraeldre, we found a trend of increasing fecundability with longer lifetime use of oral contraceptives. The adjusted fecundability ratio comparing participants who used oral contraceptives for four to five years with those who used oral contraceptives for less than two years was 1.20 (95\% confidence interval 1.05 to 1.36 ).

\section{Sensitivity analysis}

About $18.5 \%$ of participants stopped using hormonal methods of contraception and used natural or barrier methods for one or more months before attempting to conceive. The results were consistent when we excluded these women from the main analyses (eTable 2). In PRESTO, about $3.7 \%$ of women reported ever having used a progestin only oral contraceptive, and $1.0 \%$ of women $(n=89)$ used the progestin only oral contraceptive as their last method of contraception. 


\begin{tabular}{|c|c|c|c|c|c|c|c|c|c|c|}
\hline \multirow[b]{2}{*}{ Characteristic } & \multicolumn{10}{|c|}{ Last method of contraception } \\
\hline & $\begin{array}{l}\begin{array}{l}\text { Barrier } \\
(n=5497,\end{array} \\
30.6 \%)\end{array}$ & $\begin{array}{l}\text { OC } \\
(n=6735, \\
37.5 \%)\end{array}$ & $\begin{array}{l}\text { Hormonal IUD } \\
(n=1401 \text {, } \\
7.8 \%)\end{array}$ & $\begin{array}{l}\text { Copper IUD } \\
(n=717 \text {, } \\
4.0 \%)\end{array}$ & $\begin{array}{l}\text { Ring } \\
(n=477, \\
2.7 \%)\end{array}$ & $\begin{array}{l}\text { Implant } \\
(n=186, \\
1.0 \%)\end{array}$ & $\begin{array}{l}\text { Patch } \\
(n=76, \\
0.4 \%)\end{array}$ & $\begin{array}{l}\text { Injectable } \\
(n=94 \text {, } \\
0.5 \%)\end{array}$ & $\begin{array}{l}\text { Natural }^{*} \\
(n=2771, \\
15.4 \%)\end{array}$ & $\begin{array}{l}\begin{array}{l}\text { Total } \\
(n=17954, \\
100 \%)\end{array} \\
\text { (1) }\end{array}$ \\
\hline \multicolumn{11}{|l|}{ Cohort (\%) } \\
\hline Snart Gravid $(n=4435)$ & 20.3 & 35.2 & 13.8 & 13.8 & 21.4 & 5.9 & 19.7 & 12.6 & 17.5 & 24.7 \\
\hline Snart Foraeldre $(n=4768)$ & 27.1 & 31.2 & 25.6 & 45.1 & 19.7 & 9.6 & 21.1 & 3.5 & 12.6 & 26.6 \\
\hline PRESTO $(n=8575)$ & 52.6 & 33.6 & 60.6 & 41.1 & 58.9 & 84.5 & 59.2 & 83.9 & 69.9 & 48.7 \\
\hline $\begin{array}{l}\text { Mean No of pregnancy attempts } \\
\text { at study entry (cycles) }\end{array}$ & 2.0 & 2.1 & 1.9 & 1.8 & 2.1 & 1.9 & 2.1 & 2.3 & 2.0 & 2.0 \\
\hline Mean age & 29.4 & 28.6 & 30.2 & 30.3 & 29.1 & 27.5 & 27.4 & 27.7 & 29.9 & 29.2 \\
\hline Mean body mass index & 26.1 & 25.5 & 27.1 & 25.4 & 26.4 & 29.7 & 26.0 & 30.6 & 26.4 & 26.0 \\
\hline Non-Hispanic white (\%) & 91.9 & 95.5 & 91.5 & 93.8 & 91.8 & 82.8 & 89.5 & 75.6 & 87.4 & 92.4 \\
\hline Current smoker (\%) & 9.5 & 12.8 & 11.4 & 14.6 & 9.1 & 10.9 & 15.8 & 27.0 & 11.0 & 11.4 \\
\hline $\begin{array}{l}\text { Education less than college } \\
\text { degreet }(\%)\end{array}$ & 28.5 & 31.5 & 30.0 & 24.8 & 30.0 & 44.4 & 50.6 & 56.5 & 30.0 & 30.2 \\
\hline \multicolumn{11}{|l|}{ Household income $(\$ / K r) \neq(\%)$} \\
\hline$<50000 /<25000$ & 17.7 & 14.4 & 16.2 & 15.8 & 15.7 & 30.7 & 22.4 & 40.7 & 21.6 & 17.0 \\
\hline $\begin{array}{l}50000-99999 / 25000- \\
39999\end{array}$ & 31.1 & 27.7 & 32.8 & 27.9 & 32.7 & 37.3 & 38.2 & 31.4 & 33.8 & 30.5 \\
\hline $\begin{array}{l}100000-149999 / 40000- \\
64999\end{array}$ & 32.6 & 38.3 & 29.9 & 35.1 & 33.8 & 24.9 & 26.3 & 18.4 & 28.4 & 33.9 \\
\hline$\geq 150000 / \geq 65000$ & 18.6 & 19.6 & 21.1 & 21.2 & 17.8 & 7.1 & 13.2 & 9.4 & 16.3 & 18.7 \\
\hline \multicolumn{11}{|c|}{ Intercourse frequency (times/week) (\%) } \\
\hline$<1$ & 21.7 & 17.0 & 15.8 & 15.3 & 16.7 & 22.6 & 27.6 & 19.3 & 22.4 & 19.3 \\
\hline 1 & 19.1 & 19.0 & 17.6 & 20.4 & 19.9 & 16.2 & 13.2 & 17.1 & 18.6 & 18.8 \\
\hline $2-3$ & 45.1 & 45.6 & 47.1 & 44.9 & 47.1 & 40.6 & 48.7 & 31.3 & 43.2 & 45.1 \\
\hline$\geq 4$ & 14.1 & 18.5 & 19.4 & 19.4 & 16.3 & 20.6 & 10.5 & 32.4 & 15.8 & 16.8 \\
\hline $\begin{array}{l}\text { Mean length of relationship } \\
\text { (years) }\end{array}$ & 5.8 & 5.1 & 5.4 & 5.5 & 4.8 & 5.1 & 5.0 & 4.9 & 5.7 & 5.5 \\
\hline $\begin{array}{l}\text { Trying to improve chances of } \\
\text { conceiving (\%) }\end{array}$ & 73.5 & 62.0 & 71.0 & 72.0 & 64.8 & 65.1 & 68.4 & 57.3 & 72.6 & 68.3 \\
\hline History of infertility (\%) & 8.9 & 8.4 & 8.0 & 7.1 & 6.1 & 5.3 & 15.8 & 28.0 & 9.8 & 8.7 \\
\hline $\begin{array}{l}\text { History of unplanned pregnancy } \\
\text { (\%) }\end{array}$ & 28.5 & 19.2 & 31.4 & 37.1 & 20.4 & 27.6 & 22.4 & 17.8 & 31.2 & 25.8 \\
\hline History of induced abortion (\%) & 4.9 & 2.9 & 5.6 & 7.1 & 8.0 & 9.7 & 5.3 & 6.9 & 7.5 & 4.9 \\
\hline \multicolumn{11}{|l|}{ Menstrual cycle characteristics (\%) } \\
\hline Regular cycles of $<26$ days & 4.6 & 4.8 & 4.8 & 4.2 & 4.6 & 2.0 & 4.0 & 4.4 & 4.8 & 4.7 \\
\hline Regular cycles of 26-30 days & 51.4 & 43.6 & 38.0 & 61.0 & 39.2 & 25.0 & 38.2 & 33.2 & 54.0 & 47.5 \\
\hline Regular cycles of $>30$ days & 13.9 & 11.2 & 7.3 & 18.0 & 5.7 & 4.1 & 5.3 & 3.0 & 14.7 & 12.3 \\
\hline Irregular cycles & 30.1 & 40.4 & 49.9 & 16.8 & 50.5 & 69.0 & 52.6 & 59.4 & 26.5 & 35.5 \\
\hline Parous (\%) & 33.7 & 28.4 & 50.7 & 52.1 & 28.9 & 46.8 & 38.2 & 45.9 & 35.4 & 34.1 \\
\hline Endometriosis (\%) & 1.8 & 1.7 & 3.8 & 1.2 & 2.3 & 2.8 & 2.6 & 3.9 & 2.7 & 2.1 \\
\hline Polycystic ovarian syndrome (\%) & 6.7 & 6.1 & 5.9 & 6.5 & 6.6 & 7.6 & 13.2 & 10.6 & 7.4 & 6.5 \\
\hline Uterine leiomyomata (\%) & 1.6 & 1.3 & 1.3 & 1.3 & 1.7 & 0.5 & 5.3 & 1.0 & 1.7 & 1.5 \\
\hline Type 2 diabetes (\%) & 1.1 & 0.9 & 1.9 & 0.9 & 0.7 & 2.7 & 1.3 & 5.7 & 1.0 & 1.1 \\
\hline
\end{tabular}

$\mathrm{OC}=$ oral contraceptives; IUD=intrauterine device.

All characteristics, except for age (across all contraceptive methods) and characteristics of patch users were age standardized at baseline.

* Natural methods include withdrawal, calendar methods, monitoring cervical mucus or basal body temperature, and avoiding sex when fertile.

tEquivalent to fundamental education, technical education, or less than three years of higher education in Denmark.

$\neq \$ 1.00(\mathrm{Kr} 6.28 ; £ 0.77 ; € 0.84)$.

The adjusted fecundability ratio comparing users of a progestin only oral contraceptive with users of barrier methods was 1.09 (95\% confidence interval 0.87 to 1.37 ). Excluding users of progestin only oral contraceptives from the main analyses did not change our results substantially. The adjusted fecundability ratio comparing users of combined oral contraceptives with users of barrier methods was 0.99 (95\% confidence interval 0.92 to 1.07 ).

\section{Discussion}

\section{Principal findings}

In this large prospective cohort study of couples planning pregnancies and residing in Denmark,
Canada, and the US, users of oral contraceptives and some long acting reversible contraceptive methods experienced short term delays in return of fertility compared with users of barrier methods. On average, users of injectable contraceptives had the longest delay in return of normal fertility whereas users of hormonal intrauterine devices, copper intrauterine devices, and implant contraceptives had the shortest delays. Long term use of these methods did not appear to be detrimental to fertility. About $13 \%$ of women reported that they used a long acting reversible contraceptive as their last method of contraception, which is consistent with previous descriptions of use of long acting reversible contraceptives in the US. ${ }^{2}{ }^{3}$ Our findings 


\begin{tabular}{|c|c|c|c|c|c|}
\hline \multirow[b]{2}{*}{ Method } & \multirow[b]{2}{*}{ No of cycles } & \multirow[b]{2}{*}{ No of pregnancies } & \multicolumn{3}{|c|}{ Fecundability ratio $(95 \% \mathrm{Cl})$} \\
\hline & & & Model A* & Model Bt & Model C \\
\hline Barrier & 20193 & 3283 & Reference & Reference & Reference \\
\hline Oral contraceptives & 25855 & 3964 & $0.93(0.89$ to 0.97$)$ & $0.92(0.88$ to 0.96$)$ & $0.94(0.90$ to 0.98$)$ \\
\hline Hormonal IUD & 4402 & 955 & $1.22(1.15$ to 1.30$)$ & $1.23(1.15$ to 1.31$)$ & 1.14 (1.07 to 1.22$)$ \\
\hline Copper IUD & 2565 & 456 & $1.03(0.95$ to 1.13$)$ & $1.03(0.94$ to 1.12$)$ & 0.97 (0.89 to 1.06$)$ \\
\hline Ring & 1904 & 277 & $0.92(0.82$ to 1.03$)$ & 0.91 (0.81 to 1.03$)$ & 0.92 (0.82 to 1.03$)$ \\
\hline Implant & 686 & 109 & 0.94 (0.78 to 1.13$)$ & $1.05(0.87$ to 1.26$)$ & $1.03(0.85$ to 1.23$)$ \\
\hline Patch & 286 & 46 & $0.94(0.71$ to 1.23$)$ & $0.98(0.75$ to 1.29$)$ & 1.02 (0.78 to 1.33$)$ \\
\hline Injectable & 416 & 38 & 0.59 (0.43 to 0.82$)$ & 0.65 (0.47 to 0.89$)$ & $0.65(0.47$ to 0.89$)$ \\
\hline Natural§ & 10452 & 1601 & $0.96(0.90$ to 1.02$)$ & $0.97(0.92$ to 1.04$)$ & 0.96 (0.90 to 1.02$)$ \\
\hline \multicolumn{6}{|l|}{ IUDs } \\
\hline Copper & 2565 & 456 & Reference & Reference & Reference \\
\hline Hormonal & 4402 & 955 & $1.19(1.07$ to 1.31$)$ & $1.19(1.07$ to 1.33$)$ & 1.18 (1.05 to 1.33$)$ \\
\hline \multicolumn{6}{|c|}{$\begin{array}{l}\text { IUD=intrauterine device. } \\
\text { *Adjusted only for study (Snart Gravid, Snart Foraeldre, PRESTO). } \\
\text { tModels adjusted for study, age at baseline, education, race, income, body mass index, frequency of intercourse, current smoking, trying to improve } \\
\text { chances of conception, diabetes, and length of use of hormonal contraception. } \\
\text { ¥Models additionally adjusted for menstrual cycle regularity, length of menstrual cycle, parity, history of unplanned pregnancy, history of induced } \\
\text { abortion, history of infertility, endometriosis, uterine leiomyoma, and polycystic ovarian syndrome. } \\
\text { \$Natural methods include withdrawal, calendar methods, monitoring cervical mucus or basal body temperature, and avoiding sex when fertile. }\end{array}$} \\
\hline
\end{tabular}

for use of barrier methods were also consistent with previous studies that reported that $28 \%$ of women in the US of reproductive age who are cohabiting, engaged, or married use condoms. ${ }^{19}$

\section{Comparison with other studies and potential mechanisms}

The delay in return of fertility that we found was consistent with our previous study examining the use of oral contraceptives in a subset of the present Snart Gravid cohort. ${ }^{5}$ Our results were also consistent with several studies that reported slight delays in return of fertility after use of oral contraceptives, ${ }^{6}$ intrauterine devices, ${ }^{6} 8$ and implants, ${ }^{4}$ and longer delays after use of injectable contraceptives. ${ }^{4} 20$ We found little association between length of use and fecundability in the PRESTO cohort, but improved fecundability after long term use of oral contraceptives in the Snart Gravid and Snart Foraeldre studies. Our finding in the Snart Gravid and Snart Foraeldre studies is consistent with a retrospective study conducted in 8497 pregnant women in southwest England. ${ }^{7}$ This higher fecundability has been attributed to the prevention of ovulation that

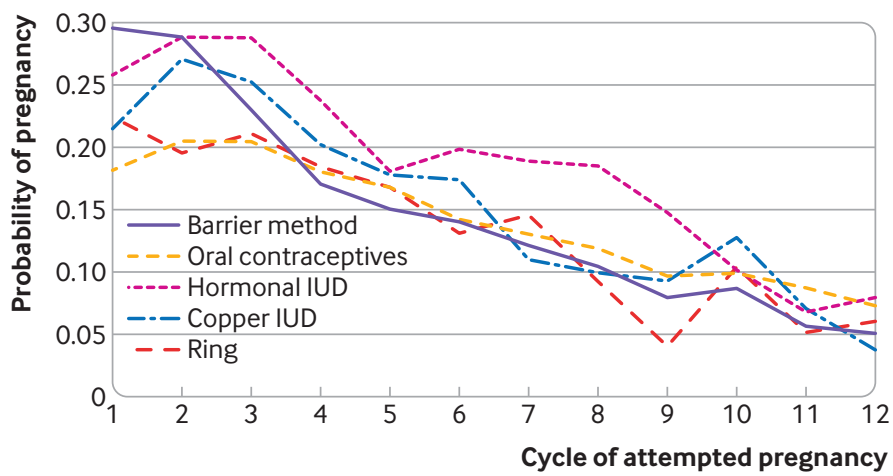

Fig 2 | Per cycle probability of conception for common contraceptive methods in the Snart Gravid, Snart Foraeldre, and PRESTO studies ( $n=17954), 2007-19$. Results are shown for barrier methods and the four most common methods of hormonal contraception. IUD=intrauterine device occurs with use of oral contraceptives, ${ }^{21}$ which might help to maintain ovarian reserve. ${ }^{22} 23$ Research on this question has shown inconsistent results, however, and potential mechanisms (eg, reduced rates of atresia) have not been fully explained. ${ }^{24-27}$

Recent use of hormonal contraceptives could influence the return of fecundability by several mechanisms. Combined oral contraceptives contain estrogen and progestin, which block the normal release of gonadotropin releasing hormone by the hypothalamus, suppressing production of follicle stimulating hormone and luteinizing hormone, and ultimately suppressing ovulation. ${ }^{21}$ Although oral contraceptives have a short half-life, prevention of ovulation, changes in cervical mucus, and thinning of the endometrium could persist after stopping oral contraceptives. The vaginal ring and transdermal patch act by a similar mechanism ${ }^{28} 29$ and might continue to suppress ovarian function immediately after stopping use of these contraceptives. ${ }^{30}$ Progestin only injectable, implant, and oral contraceptives also act at the pituitary and hypothalamic levels to suppress ovulation and have effects on cervical mucus and endometrial thickness. ${ }^{21}$ Also, injectable contraceptives contain substantially higher dosages of progestin than other contraceptive methods as they are designed to prevent pregnancy for at least 90 days after injection. ${ }^{3132}$ The most common type of injectable contraceptive is depot medroxyprogesterone acetate (DMPA), which is given intramuscularly in a $150 \mathrm{mg}$ dose and has a half-life of 50 days. Levels of DMPA are detectable $(<100 \mathrm{pg} / \mathrm{mL})$ for $120-200$ days after injection. ${ }^{33}$ The longer half-life of DMPA could explain the overall reduced fecundability and longer delay in return of fertility in users of injectable contraceptives. Our findings also agree with a previous study that reported a threefold longer time to pregnancy for users of injectable contraceptives than users of condoms after stopping contraception. ${ }^{4}$ The characteristics of users of injectable contraceptives differed from those of 


\begin{tabular}{|c|c|c|c|c|c|c|}
\hline Method & Cycle 1 & Cycle 2 & Cycle 3 & Cycle 4 & Cycles 5-8 & Cycles $9-12$ \\
\hline \multicolumn{7}{|l|}{ Barrier } \\
\hline No of cycles & 1229 & 2317 & 2356 & 2294 & 7833 & 4164 \\
\hline No of pregnancies & 363 & 671 & 540 & 390 & 1024 & 295 \\
\hline Adjusted FR $(95 \% \mathrm{Cl})^{\star}$ & Reference & Reference & Reference & Reference & Reference & Reference \\
\hline Adjusted FR (95\% Cl)† & Reference & Reference & Reference & Reference & Reference & Reference \\
\hline \multicolumn{7}{|l|}{ Oral contraceptives } \\
\hline No of cycles & 1284 & 2894 & 3166 & 3142 & 10293 & 5076 \\
\hline No of pregnancies & 234 & 593 & 648 & 568 & 1459 & 462 \\
\hline Adjusted FR $(95 \% \mathrm{Cl})^{\star}$ & $0.66(0.57$ to 0.77$)$ & $0.73(0.66$ to 0.81$)$ & 0.89 (0.80 to 0.99$)$ & $1.06(0.94$ to 1.20$)$ & $1.06(0.98$ to 1.14$)$ & $1.17(1.01$ to 1.35$)$ \\
\hline Adjusted FR $(95 \% \mathrm{Cl}) \dagger$ & 0.69 (0.58 to 0.81$)$ & 0.77 (0.70 to 0.85$)$ & 0.91 (0.82 to 1.01) & 1.07 (0.94 to 1.21$)$ & $1.05(0.97$ to 1.14$)$ & $1.14(0.98$ to 1.33$)$ \\
\hline \multicolumn{7}{|l|}{ Hormonal IUD } \\
\hline No of cycles & 295 & 658 & 643 & 571 & 1610 & 625 \\
\hline No of pregnancies & 76 & 190 & 185 & 135 & 303 & 66 \\
\hline Adjusted FR $(95 \% \mathrm{Cl})^{\star}$ & $0.89(0.72$ to 1.10$)$ & $0.98(0.85$ to 1.13$)$ & $1.25(1.08$ to 1.44$)$ & $1.41(1.18$ to 1.68$)$ & $1.42(1.25$ to 1.60$)$ & 1.47 (1.14 to 1.90$)$ \\
\hline Adjusted FR $(95 \% \mathrm{Cl}) \dagger$ & $0.81(0.65$ to 1.00$)$ & 0.92 (0.80 to 1.07$)$ & $1.20(1.04$ to 1.39$)$ & 1.31 (1.09 to 1.57$)$ & 1.31 (1.15 to 1.49$)$ & $1.40(1.08$ to 1.82$)$ \\
\hline \multicolumn{7}{|l|}{ Copper IUD } \\
\hline No of cycles & 194 & 355 & 330 & 298 & 931 & 457 \\
\hline No of pregnancies & 42 & 96 & 83 & 60 & 135 & 40 \\
\hline Adjusted FR $(95 \% \mathrm{Cl})^{*}$ & $0.74(0.56$ to 0.98$)$ & $0.97(0.80$ to 1.17$)$ & $1.11(0.91$ to 1.36$)$ & 1.14 (0.88 to 1.47$)$ & $1.08(0.91$ to 1.27$)$ & $1.17(0.85$ to 1.61$)$ \\
\hline Adjusted FR $(95 \% \mathrm{Cl}) \dagger$ & $0.71(0.53$ to 0.94$)$ & $0.93(0.77$ to 1.12$)$ & $1.05(0.85$ to 1.29$)$ & $1.07(0.83$ to 1.38$)$ & $1.02(0.86$ to 1.21$)$ & $1.09(0.78$ to 1.51$)$ \\
\hline \multicolumn{7}{|l|}{ Ring } \\
\hline No of cycles & 94 & 194 & 228 & 217 & 751 & 420 \\
\hline No of pregnancies & 21 & 38 & 48 & 40 & 103 & 27 \\
\hline Adjusted FR $(95 \% \mathrm{Cl})^{*}$ & $0.82(0.55$ to 1.20$)$ & 0.71 (0.52 to 0.95$)$ & 0.95 (0.73 to 1.23$)$ & 1.05 (0.78 to 1.42$)$ & $1.04(0.86$ to 1.27$)$ & 0.90 (0.61 to 1.32$)$ \\
\hline Adjusted FR $(95 \% \mathrm{Cl}) \dagger$ & 0.78 (0.52 to 1.15$)$ & $0.72(0.54$ to 0.97$)$ & 0.96 (0.74 to 1.25$)$ & 1.05 (0.77 to 1.42$)$ & 1.04 (0.86 to 1.27$)$ & $0.88(0.60$ to 1.29$)$ \\
\hline \multicolumn{7}{|l|}{ Implant } \\
\hline No of cycles & 40 & 78 & 87 & 84 & 262 & 135 \\
\hline No of pregnancies & 9 & 21 & 15 & 13 & 39 & 12 \\
\hline Adjusted FR $(95 \% \mathrm{Cl})^{*}$ & $0.72(0.41$ to 1.30$)$ & 0.83 (0.55 to 1.27$)$ & 0.73 (0.44 to 1.20$)$ & 0.85 (0.48 to 1.49$)$ & $1.15(0.85$ to 1.56$)$ & 1.34 (0.77 to 2.32$)$ \\
\hline Adjusted FR $(95 \% \mathrm{Cl}) \dagger$ & $0.62(0.34$ to 1.11$)$ & 0.91 (0.59 to 1.39) & $0.86(0.52$ to 1.40$)$ & $0.92(0.53$ to 1.62$)$ & $1.29(0.95$ to 1.76$)$ & 1.34 (0.77 to 2.33$)$ \\
\hline \multicolumn{7}{|l|}{ Patch } \\
\hline No of cycles & 13 & 32 & 39 & 40 & 112 & 50 \\
\hline No of pregnancies & 1 & 7 & 6 & 7 & 17 & 8 \\
\hline Adjusted FR $(95 \% \mathrm{Cl})^{*}$ & $0.25(0.04$ to 1.63$)$ & 0.67 (0.33 to 1.38$)$ & $0.67(0.32$ to 1.41$)$ & 0.99 (0.49 to 2.01) & $1.19(0.75$ to 1.86$)$ & $2.23(1.17$ to 4.25$)$ \\
\hline Adjusted FR $(95 \% \mathrm{Cl}) \dagger$ & $0.27(0.04$ to 1.67$)$ & $0.71(0.35$ to 1.45$)$ & $0.78(0.37$ to 1.62$)$ & 1.06 (0.53 to 2.14$)$ & $1.28(0.81$ to 2.02$)$ & $2.30(1.20$ to 4.42$)$ \\
\hline \multicolumn{7}{|l|}{ Injectable } \\
\hline No of cycles & 14 & 30 & 45 & 50 & 178 & 99 \\
\hline No of pregnancies & 1 & 2 & 1 & 2 & 21 & 11 \\
\hline Adjusted FR $(95 \% \mathrm{Cl})^{*}$ & $0.22(0.03$ to 1.45$)$ & 0.20 (0.04 to 0.99$)$ & $0.13(0.02$ to 0.87$)$ & $0.34(0.10$ to 1.20$)$ & $0.90(0.59$ to 1.37$)$ & 1.72 (0.98 to 3.04$)$ \\
\hline Adjusted FR $(95 \% \mathrm{Cl}) \dagger$ & $0.23(0.04$ to 1.44$)$ & $0.23(0.05$ to 1.14$)$ & $0.13(0.02$ to 0.91$)$ & 0.39 (0.11 to 1.36$)$ & $0.94(0.61$ to 1.46$)$ & $1.81(1.02$ to 3.19$)$ \\
\hline \multicolumn{7}{|l|}{ Natural } \\
\hline No of cycles & 553 & 1199 & 1271 & 1245 & 4006 & 2178 \\
\hline No of pregnancies & 146 & 289 & 262 & 237 & 519 & 148 \\
\hline Adjusted FR $(95 \% \mathrm{Cl})^{*}$ & 0.89 (0.74 to 1.07$)$ & $0.83(0.73$ to 0.95$)$ & 0.92 (0.80 to 1.06$)$ & 1.13 (0.96 to 1.33$)$ & 1.01 (0.91 to 1.12$)$ & $1.02(0.83$ to 1.26$)$ \\
\hline Adjusted FR $(95 \% \mathrm{Cl}) \dagger$ & $0.90(0.75$ to 1.08$)$ & $0.85(0.75$ to 0.97$)$ & $0.93(0.81$ to 1.07$)$ & $1.07(0.91$ to 1.26$)$ & $1.02(0.92$ to 1.14$)$ & $0.99(0.79$ to 1.23$)$ \\
\hline \multicolumn{7}{|c|}{$\begin{array}{l}\text { FR=fecundability ratio; IUD=intrauterine device. } \\
\text { *Adjusted for study (Snart Gravid, Snart Foraeldre, PRESTO). } \\
\text { tModels adjusted for study, age at baseline, education, race, income, body mass index, frequency of intercourse, current smoking, trying to improve chances of conception, diabetes, length } \\
\text { of use of hormonal contraception, menstrual cycle regularity, length of menstrual cycle, parity, history of unplanned pregnancy, history of induced abortion, history of infertility, endometriosis, } \\
\text { uterine leiomyoma, and polycystic ovarian syndrome. }\end{array}$} \\
\hline
\end{tabular}

users of barrier method in our study, however. Residual confounding by unmeasured factors, such as overall health condition and knowledge of reproductive health, might explain part of the association seen.

The average per cycle probability of conception was about 20\% higher in women who used the hormonal intrauterine device than in those who used barrier methods. We expected that women with proven fertility (that is, women with previous pregnancies) would be more likely to use intrauterine devices and to have greater fecundability than women who used barrier methods. Although users of intrauterine devices were more likely to be parous than users of other methods, adjustment for parity and other indicators of underlying fertility did not explain our findings. Also, the fecundability ratio comparing users of hormonal intrauterine devices with users of barrier methods (1.14; 95\% confidence interval 1.07 to 1.22 ) was similar to the fecundability ratio comparing users of hormonal intrauterine devices with users of copper intrauterine devices $(1.18 ; 95 \%$ confidence interval 1.05 to 1.33 ). This finding suggests that users of hormonal intrauterine devices have improved fecundability relative to users of barrier methods and copper intrauterine devices, and that this effect is not confounded by underlying fertility. 


\begin{tabular}{|c|c|c|c|c|c|c|}
\hline \multirow[b]{2}{*}{ Method } & \multicolumn{3}{|l|}{ Category 1} & \multicolumn{3}{|l|}{ Category 2} \\
\hline & No of cycles & $\begin{array}{l}\text { No of } \\
\text { pregnancies }\end{array}$ & Adjusted FR $(95 \% \mathrm{Cl})^{*}$ & No of cycles & $\begin{array}{l}\text { No of } \\
\text { pregnancies }\end{array}$ & Adjusted FR $(95 \% \mathrm{Cl})^{*}$ \\
\hline \multicolumn{7}{|c|}{ Country (Denmark v US and Canada) } \\
\hline Barrier & 8971 & 1583 & Reference & 11076 & 1675 & Reference \\
\hline Oral contraceptives & 17324 & 2661 & $0.90(0.85$ to 0.96$)$ & 8333 & 1275 & $1.00(0.93$ to 1.07$)$ \\
\hline Hormonal IUD & 1715 & 368 & $1.06(0.96$ to 1.17$)$ & 2632 & 560 & $1.22(1.11$ to 1.33$)$ \\
\hline Copper IUD & 1378 & 269 & 0.98 (0.87 to 1.10$)$ & 1166 & 182 & 0.91 (0.79 to 1.05$)$ \\
\hline Ring & 785 & 113 & $0.89(0.74$ to 1.06$)$ & 1106 & 162 & $0.97(0.83$ to 1.14$)$ \\
\hline Implant & 106 & 17 & $0.97(0.63$ to 1.48$)$ & 566 & 85 & 1.05 (0.85 to 1.29$)$ \\
\hline Patch & 129 & 19 & $0.89(0.59$ to 1.35$)$ & 155 & 27 & 1.11 (0.78 to 1.58$)$ \\
\hline Injectable & 74 & 9 & $0.79(0.43$ to 1.45$)$ & 345 & 26 & 0.63 (0.44 to 0.91$)$ \\
\hline Naturalt & 2971 & 490 & $0.92(0.84$ to 1.02$)$ & 7372 & 1085 & $0.98(0.91$ to 1.06$)$ \\
\hline \multicolumn{7}{|l|}{ Age $(<30 v \geq 30)$} \\
\hline Barrier & 13962 & 2390 & Reference & 6231 & 893 & Reference \\
\hline Oral contraceptives & 21645 & 3341 & $0.96(0.87$ to 1.06$)$ & 4210 & 623 & 1.01 (0.92 to 1.12$)$ \\
\hline Hormonal IUD & 2933 & 640 & $1.14(1.00$ to 1.30$)$ & 1469 & 315 & $1.29(1.14$ to 1.46$)$ \\
\hline Copper IUD & 1840 & 355 & $0.94(0.76$ to 1.17$)$ & 725 & 101 & 0.89 (0.73 to 1.09$)$ \\
\hline Ring & 1370 & 197 & 0.91 (0.73 to 1.13) & 534 & 80 & $1.01(0.81$ to 1.26$)$ \\
\hline Implant & 496 & 82 & $1.04(0.81$ to 1.33$)$ & 190 & 27 & $1.02(0.70$ to 1.48$)$ \\
\hline Patch & 242 & 37 & $0.95(0.61$ to 1.50$)$ & 44 & 9 & $1.42(0.83$ to 2.41$)$ \\
\hline Injectable & 342 & 32 & $0.62(0.41$ to 0.93$)$ & 74 & 6 & 0.59 (0.23 to 1.49$)$ \\
\hline Naturalt & 6336 & 1031 & 0.99 (0.88 to 1.10$)$ & 4116 & 570 & $1.00(0.90$ to 1.11$)$ \\
\hline \multicolumn{7}{|c|}{ Body mass index $(<30 v \geq 30)$} \\
\hline Barrier & 15397 & 2703 & Reference & 4796 & 580 & Reference \\
\hline Oral contraceptives & 21046 & 3399 & 0.93 (0.89 to 0.98$)$ & 4809 & 565 & 0.96 (0.84 to 1.09$)$ \\
\hline Hormonal IUD & 3143 & 749 & $1.15(1.07$ to 1.24$)$ & 1259 & 206 & $1.15(0.98$ to 1.35$)$ \\
\hline Copper IUD & 2129 & 391 & 0.98 (0.89 to 1.08$)$ & 436 & 65 & 0.95 (0.74 to 1.22$)$ \\
\hline Ring & 1470 & 227 & $0.92(0.81$ to 1.04$)$ & 434 & 50 & 0.91 (0.68 to 1.21$)$ \\
\hline Implant & 345 & 71 & $1.13(0.90$ to 1.41$)$ & 341 & 38 & $0.89(0.65$ to 1.21$)$ \\
\hline Patch & 211 & 35 & $1.00(0.74$ to 1.36$)$ & 75 & 11 & 0.95 (0.53 to 1.70$)$ \\
\hline Injectable & 239 & 30 & 0.75 (0.53 to 1.06$)$ & 177 & 8 & $0.44(0.21$ to 0.90$)$ \\
\hline Naturalt & 7948 & 1323 & $0.96(0.90$ to 1.02$)$ & 2504 & 278 & $0.96(0.82$ to 1.12$)$ \\
\hline \multicolumn{7}{|c|}{ No of cycle attempts at study entry $(0-2 \times 3-6)$} \\
\hline Barrier & 13323 & 2450 & Reference & 6870 & 833 & Reference \\
\hline Oral contraceptives & 17307 & 2804 & 0.89 (0.85 to 0.94$)$ & 8548 & 1160 & 1.07 (0.98 to 1.17$)$ \\
\hline Hormonal IUD & 3236 & 719 & $1.08(1.00$ to 1.16$)$ & 1166 & 236 & $1.41(1.22$ to 1.61$)$ \\
\hline Copper IUD & 1833 & 350 & $0.96(0.86$ to 1.06$)$ & 732 & 106 & $1.03(0.85$ to 1.26$)$ \\
\hline Ring & 1261 & 202 & 0.91 (0.79 to 1.04$)$ & 643 & 75 & $0.96(0.75$ to 1.21$)$ \\
\hline Implant & 493 & 80 & $0.96(0.78$ to 1.19$)$ & 193 & 29 & 1.25 (0.87 to 1.78$)$ \\
\hline Patch & 214 & 33 & 0.91 (0.67 to 1.25$)$ & 72 & 13 & 1.43 (0.85 to 2.40$)$ \\
\hline Injectable & 297 & 30 & $0.48(0.32$ to 0.74$)$ & 119 & 18 & $1.15(0.73$ to 1.80$)$ \\
\hline Naturalt & 7198 & 1178 & 0.92 (0.86 to 0.99$)$ & 3254 & 423 & $1.08(0.95$ to 1.23$)$ \\
\hline \multicolumn{7}{|c|}{ Infertility (no history v existing history) } \\
\hline Barrier & 18273 & 3082 & Reference & 1920 & 201 & Reference \\
\hline Oral contraceptives & 23973 & 3740 & $0.98(0.91$ to 1.05$)$ & 1882 & 224 & $1.11(0.91$ to 1.35$)$ \\
\hline Hormonal IUD & 4030 & 886 & $1.20(1.10$ to 1.32$)$ & 372 & 69 & $1.73(1.32$ to 2.26$)$ \\
\hline Copper IUD & 2378 & 427 & $0.90(0.77$ to 1.05$)$ & 187 & 29 & 1.14 (0.78 to 1.67$)$ \\
\hline Ring & 1776 & 267 & 0.96 (0.83 to 1.12$)$ & 128 & 10 & $0.69(0.32$ to 1.52$)$ \\
\hline Implant & 644 & 105 & 1.07 (0.86 to 1.33$)$ & 42 & 4 & $1.20(0.45$ to 3.21$)$ \\
\hline Patch & 249 & 41 & $1.03(0.70$ to 1.52$)$ & 37 & 5 & $1.20(0.49$ to 2.96$)$ \\
\hline Injectable & 306 & 28 & $0.58(0.38$ to 0.87$)$ & 110 & 10 & 1.07 (0.53 to 2.15$)$ \\
\hline Naturalt & 9429 & 1501 & $0.97(0.90$ to 1.05$)$ & 1023 & 100 & $1.05(0.78$ to 1.41$)$ \\
\hline \multicolumn{7}{|c|}{ Parity (nulliparous v parous) } \\
\hline Barrier & 14208 & 2070 & Reference & 5985 & 1213 & Reference \\
\hline Oral contraceptives & 19885 & 2840 & 0.95 (0.90 to 1.00$)$ & 5970 & 1124 & 0.93 (0.86 to 1.00$)$ \\
\hline Hormonal IUD & 2188 & 443 & $1.25(1.13$ to 1.37$)$ & 2214 & 512 & 1.07 (0.97 to 1.17$)$ \\
\hline Copper IUD & 1325 & 205 & $0.97(0.85$ to 1.11$)$ & 1240 & 251 & 0.95 (0.84 to 1.07$)$ \\
\hline Ring & 1423 & 202 & 0.98 (0.86 to 1.13$)$ & 481 & 75 & $0.79(0.62$ to 1.00$)$ \\
\hline Implant & 424 & 60 & $0.99(0.76$ to 1.31$)$ & 262 & 49 & $1.09(0.85$ to 1.40$)$ \\
\hline Patch & 188 & 27 & $1.02(0.71$ to 1.45$)$ & 98 & 19 & $1.04(0.69$ to 1.55$)$ \\
\hline Injectable & 252 & 24 & $0.75(0.51$ to 1.11$)$ & 164 & 14 & $0.53(0.31$ to 0.91$)$ \\
\hline Naturalt & 6934 & 971 & $0.99(0.91$ to 1.06$)$ & 3518 & 630 & $0.91(0.83$ to 1.00$)$ \\
\hline
\end{tabular}




\begin{tabular}{|c|c|c|c|c|c|c|}
\hline \multicolumn{7}{|l|}{ Table 4 | Continued } \\
\hline \multirow[b]{2}{*}{ Method } & \multicolumn{3}{|l|}{ Category 1} & \multicolumn{3}{|l|}{ Category 2} \\
\hline & No of cycles & $\begin{array}{l}\text { No of } \\
\text { pregnancies }\end{array}$ & Adjusted FR $(95 \% \mathrm{CI})^{*}$ & No of cycles & $\begin{array}{l}\text { No of } \\
\text { pregnancies }\end{array}$ & Adjusted FR $(95 \% \mathrm{CI})$ * \\
\hline \multicolumn{7}{|c|}{ Menstrual cycle (regular v irregular) } \\
\hline Barrier & 14221 & 2356 & Reference & 5972 & 927 & Reference \\
\hline Oral contraceptives & 15580 & 2429 & $0.95(0.90$ to 1.01$)$ & 10275 & 1535 & $0.94(0.86$ to 1.04$)$ \\
\hline Copper IUD & 2205 & 389 & $0.96(0.87$ to 1.06$)$ & 360 & 67 & $1.08(0.86$ to 1.35$)$ \\
\hline Ring & 990 & 129 & $0.83(0.70$ to 0.99$)$ & 914 & 148 & $1.01(0.87$ to 1.16$)$ \\
\hline Implant & 222 & 35 & $1.02(0.75$ to 1.40$)$ & 464 & 74 & 1.03 (0.84 to 1.28$)$ \\
\hline Patch & 127 & 26 & $1.19(0.85$ to 1.68$)$ & 159 & 20 & 0.86 (0.58 to 1.28$)$ \\
\hline Injectable & 236 & 16 & $0.51(0.32$ to 0.81$)$ & 180 & 22 & $0.86(0.56$ to 1.33$)$ \\
\hline
\end{tabular}

Hormonal intrauterine devices release levonorgestrel, a progestin that creates a spermicidal environment and prevents fertilization or implantation. Unlike other hormonal methods, the hormonal intrauterine device does not suppress ovulation. $^{34}$ Similarly, the copper intrauterine device prevents fertilization and implantation but has no effect on ovulation. The mechanisms by which copper intrauterine devices prevent pregnancy are not fully understood, however. Most research on intrauterine devices and fecundability has not examined intrauterine devices separately by type, ${ }^{689}$ with the exception of one randomized trial conducted in $1993 .{ }^{35}$ In the randomized trial, the investigators evaluated fecundability after removal of the intrauterine device and found slightly higher pregnancy rates in women assigned to the levonorgestrel intrauterine device compared with the copper intrauterine device.

\section{Limitations of the study}

This study had several limitations. First, some misclassification of cycles was likely because our calculation of time-to-pregnancy relied on reported length of the menstrual cycle ${ }^{36}$ and date of the last menstrual period. $^{11}$ Misclassification could also have arisen if participants interpreted the question, "Did you wait a few months after stopping hormonal contraception before trying to get pregnant?” as asking about two or three months specifically. The extent of misclassification is likely to be small, however, because $45 \%$ of participants who reported waiting indicated that they waited more than three months, and $16 \%$ reported having waited less than 2 months. Second, confidence intervals were wide in the analyses of less commonly used contraceptive methods, limiting our ability to identify the timing of return of fertility. Third, we did not collect data on the date of the last injection for women who used injectable contraceptives. This lack of data limited our ability to determine the recency of use in women who used injectable contraceptives continuously and to evaluate potential misclassification of wait time in women who reported stopping injectable contraceptives a few months before trying to conceive.

In this study, two potential sources of selection bias were identified. Study cohorts were based on selfselection and were volunteers. Women who volunteer to participate in research might differ from those who decline. We believe that our findings are internally valid and externally applicable to those planning pregnancies, however, because the physiological mechanisms underlying the effects that we examined are unlikely to vary substantially between women who did and did not participate. Also, women who conceive immediately after stopping contraception might be less likely to enroll in the study. About $50 \%$ of study participants reported that the number of attempts at conceiving was less than two menstrual cycles at study entry, however. This finding indicates that we were successful in recruiting couples at the beginning of their attempts to conceive. We also found minimal evidence of bias in a previous empirical evaluation of the potential for selection bias in Snart Gravid. ${ }^{37}$ Overall, we expect any potential selection bias to be minimal.

For our analysis of length of use, two limitations were identified. Precision was limited because a detailed history of use of all types of hormonal contraceptives was available only for participants in PRESTO. Also, reporting of contraceptive methods is likely to be less accurate for methods used in the distant past than those used recently. Given the prospective cohort design, any errors in recall of contraception are expected to be unrelated to outcome, leading to reduced associations for extreme categories of length of contraception use.

\section{Conclusions}

In this large prospective investigation, we examined the association between pregravid use of contraceptives and subsequent fecundability. We considered several less studied long acting reversible contraceptive methods, including implants and injectable contraceptives, and also individual intrauterine device types. Our findings suggested that return of normal 
fertility varies substantially by contraceptive method. Overall, we found that use of intrauterine devices and implant contraceptives was associated with short delays in the return of fertility, with injectable contraceptives showing the longest delay (about five to eight menstrual cycles). Our results, although imprecise, indicate little or no lasting effect of long term use of these methods on fecundability. As the use of long acting reversible contraceptive methods becomes more common worldwide, these findings might inform clinical recommendations on contraceptive decision making. Understanding the comparative effects of different contraceptives on fecundity is essential for family planning, counselling for contraception, and management of infertility.

We thank Anders $\mathrm{H}$ Riis and Kristen A Hahn for their assistance with data management and quality control; David A Savitz and Karen C Schliep for their thoughtful comments on previous versions of this manuscript; and all the study participants for their involvement and use of their data in these analyses.

Contributors: JJY was responsible for the statistical analyses, interpretation of the results, manuscript writing, revision, and finalization. KAB was responsible for formulation of the study hypotheses and study design, statistical analyses, interpretation of the results, manuscript writing, and revision. EEH, EMM, and HTS were responsible for study design, development and implementation of the study cohorts, and manuscript revision. AKW was responsible for development and implementation of the study cohorts, statistical analysis, and manuscript revision. KJR and KFH were responsible for study design, analysis methods, interpretation of the results, and manuscript revision. LAW was responsible for study design, development and implementation of the study cohorts, interpretation of the results, manuscript writing, and manuscript revision. JJY was the study guarantor. The corresponding author attests that all listed authors meet authorship criteria and that no others meeting the criteria have been omitted.

Funding: This work was supported by the Eunice Kennedy Shriver National Institute of Child Health and Human Development, National Institutes of Health (R01-HD060680, R01-HD086742, R21HD050264, R21-HD072326, T32-HD052458). The funders had no role in the study design, data collection, analysis and interpretation of data, writing of the report, or the decision to submit the paper for publication.

Competing interests: All authors have completed the ICMJE uniform disclosure form at www.icmje.org/coi_disclosure.pdf (available on request from the corresponding author) and declare: support from the National Institute of Child Health and Human Development and Danish Medical Research Council for the submitted work. KJR is an employee of RTI Health Solutions, an independent non-profit research organization that does work for government agencies and pharmaceutical companies. LAW does consultancy for AbbVie. KAB is an employee of Vertex Pharmaceuticals. In the last three years, Pregnancy Study Online has accepted in-kind donations from: Sandstone Diagnostics, Swiss Precision Diagnostics, Kindara.com, and FertilityFriend.com. The Department of Clinical Epidemiology, Aarhus University Hospital, receives funding for other studies from companies in the form of research grants to (and administered by) Aarhus University. None of these studies has any relation to the present study. The authors report no other relationships or activities that could appear to have influenced the submitted work.

Ethical approval: The institutional review board of Boston University Medical Campus approved the study protocol: PRESTO H-31848; Snart Gravid H-25361; Snart Foraeldre H-28795. Because no biological material was included in Snart Gravid and Snart Foraeldre, approval by an ethics committee in Denmark was not required. Snart Gravid was registered by the Danish Data Protection Agency (201341-1922) and Snart Foraeldre was registered at Aarhus University to comply with Danish law on data protection (2016-051-000001, No 431)

Data sharing: Data from Snart Gravid, Snart Foraeldre, and PRESTO are not yet publicly available.

The corresponding author attests that this manuscript is an honest, accurate, and transparent account of the study being reported; that no important aspects of the study have been omitted; and that any discrepancies from the study as originally planned have been explained.

Dissemination to participants and related patient and public communities: Results of the study will be accessible to participants and the public through the study websites.

Provenance and peer review: Not commissioned; externally peer reviewed.

This is an Open Access article distributed in accordance with the Creative Commons Attribution Non Commercial (CC BY-NC 4.0) license, which permits others to distribute, remix, adapt, build upon this work non-commercially, and license their derivative works on different terms, provided the original work is properly cited and the use is noncommercial. See: http://creativecommons.org/licenses/by-nc/4.0/.

1 United Nations DoEaSA, Population Division. Contraceptive use by method 2019: data booklet. (ST/ESA/SERA/435). 2019.

2 Daniels K, Abma JC. Current contraceptive status among women aged 15-49: United States, 2015-2017. US Department of Health and Human Services, Centers for Disease Control and Prevention, National Center for Health Statistics; 2018.

3 Branum AM, Jones J. Trends in long-acting reversible contraception use among U.S. women aged 15-44. NCHS Data Brief 2015; 188:1-8.

4 Hassan MA, Killick SR. Is previous use of hormonal contraception associated with a detrimental effect on subsequent fecundity? Hum Reprod 2004:19:344-51. doi:10.1093/humrep/deh058

5 Mikkelsen EM, Riis AH, Wise LA, Hatch EE, Rothman KJ, Sørensen HT. Pre-gravid oral contraceptive use and time to pregnancy: a Danish prospective cohort study. Hum Reprod 2013;28:1398-405. doi:10.1093/humrep/det023

6 Linn S, Schoenbaum SC, Monson RR, Rosner B, Ryan KJ. Delay in conception for former 'pill' users. JAMA 1982;247:629-32. doi:10.1001/jama.1982.03320300033018

7 Farrow A, Hull MG, Northstone K, Taylor H, Ford WC, Golding J. Prolonged use of oral contraception before a planned pregnancy is associated with a decreased risk of delayed conception. Hum Reprod 2002;17:2754-61. doi:10.1093/humrep/17.10.2754

8 Kaplan B, Nahum R, Yairi Y, et al. Use of various contraceptive methods and time of conception in a community-based population. Eur J Obstet Gynecol Reprod Biol 2005;123:72-6. doi:10.1016/j. ejogrb.2005.06.033

9 Stoddard AM, Xu H, Madden T, Allsworth JE, Peipert JF. Fertility after intrauterine device removal: a pilot study. Eur J Contracept Reprod Health Care 2015;20:223-30. doi:10.3109/13625187.2015.1010 639

10 Mikkelsen EM, Hatch EE, Wise LA, Rothman KJ, Riis A, Sørensen HT. Cohort profile: the Danish web-based pregnancy planning study'Snart-Gravid'. Int J Epidemiol 2009;38:938-43. doi:10.1093/ije/ dyn191

11 Wise LA, Rothman KJ, Mikkelsen EM, et al. Design and conduct of an internet-based preconception cohort study in North America: pregnancy study online. Paediatr Perinat Epidemiol 2015;29:36071. doi:10.1111/ppe.12201

12 Huybrechts KF, Mikkelsen EM, Christensen T, et al. A successful implementation of e-epidemiology: the Danish pregnancy planning study ‘Snart-Gravid’. Eur / Epidemiol 2010;25:297-304. doi:10.1007/s10654-010-9431-y

13 Cox DR. Regression models and life-tables. J R Stat Soc B 1972:34:187-220. doi:10.1111/j.2517-6161.1972.tb00899x

14 Weinberg CR, Wilcox AJ, Baird DD. Reduced fecundability in women with prenatal exposure to cigarette smoking. Am J Epidemiol 1989;129:1072-8. doi:10.1093/oxfordjournals.aje. a115211

15 Howards PP, Hertz-Picciotto I, Poole C. Conditions for bias from differential left truncation. Am J Epidemiol 2007;165:444-52. doi:10.1093/aje/kwk027

16 Schisterman EF, Cole SR, Ye A, Platt RW. Accuracy loss due to selection bias in cohort studies with left truncation. Paediatr Perinat Epidemiol 2013;27:491-502. doi:10.1111/ppe.12073

17 Legro RS, Arslanian SA, Ehrmann DA, et al, Endocrine Society. Diagnosis and treatment of polycystic ovary syndrome: an Endocrine Society clinical practice guideline. / Clin Endocrinol Metab 2013:98:4565-92. doi:10.1210/jc.2013-2350

18 SAS Institute. SAS/Stat 9.4 user's guide. Cary, NC. 2011.

19 Copen CE. Condom use during sexual intercourse among women and men aged 15-44 in the United States: 2011-2015 National Survey of Family Growth. Natl Health Stat Report 2017;105:1-18.

20 Paulen ME, Curtis KM. When can a woman have repeat progestogen-only injectables--depot medroxyprogesterone acetate or norethisterone enantate?Contraception 2009;80:391-408. doi:10.1016/j.contraception.2009.03.023 
21 Rivera R, Yacobson I, Grimes D. The mechanism of action of hormonal contraceptives and intrauterine contraceptive devices. Am J Obstet Gynecol 1999;181:1263-9. doi:10.1016/S0002 9378(99)70120-1

22 Durlinger AL, Visser JA, Themmen AP. Regulation of ovarian function: the role of anti-Müllerian hormone. Reproduction 2002:124:601-9. doi:10.1530/rep.0.1240601

23 Gromoll J, Simoni M. Genetic complexity of FSH receptor function. Trends Endocrinol Metab 2005;16:368-73. doi:10.1016/j. tem.2005.05.011

24 Beltadze K, Barbakadze L. Ovarian reserve in the women of late reproductive age after conservative treatment of polycystic ovary syndrome in adolescence. Georgian Med News 2015;238:27-31

25 Schuh-Huerta SM, Johnson NA, Rosen MP, Sternfeld B, Cedars MI, Reijo Pera RA. Genetic variants and environmental factors associated with hormonal markers of ovarian reserve in Caucasian and African American women. Hum Reprod 2012;27:594-608. doi:10.1093/ humrep/der391

26 Dólleman M, Verschuren WM, Eijkemans MJ, et al. Reproductive and lifestyle determinants of anti-Müllerian hormone in a large population-based study. J Clin Endocrinol Metab 2013;98:2106-15. doi:10.1210/jc.2012-3995

27 Gold EB, Bromberger J, Crawford S, et al. Factors associated with age at natural menopause in a multiethnic sample of midlife women. $\mathrm{Am}$ Epidemiol 2001;153:865-74. doi:10.1093/aje/153.9.865

28 Mulders TM, Dieben TO. Use of the novel combined contraceptive vaginal ring NuvaRing for ovulation inhibition. Fertil Steril 2001;75:865-70. doi:10.1016/S0015-0282(01)01689-2

29 Goa KL, Warner GT, Easthope SE. Transdermal ethinylestradiol/ norelgestromin: a review of its use in hormonal contraception. Treat Endocrinol 2003;2:191-206. doi:10.2165/00024677 200302030-00005
30 Gnoth C, Frank-Herrmann P, Schmoll A, Godehardt E, Freundl G. Cycle characteristics after discontinuation of oral contraceptives. Gynecol Endocrinol 2002;16:307-17. doi:10.1080/gye.16.4.307.317

31 Jain J, Dutton C, Nicosia A, Wajszczuk C, Bode FR, Mishell DRJr. Pharmacokinetics, ovulation suppression and return to ovulation following a lower dose subcutaneous formulation of Depo-Provera. Contraception 2004;70:11-8. doi:10.1016/j. contraception.2004.01.011

32 Mishell DRJr. Effect of 6-alpha-methyl-17-alpha-hydroxyprogesterone on urinary excretion of luteinizing hormone. Am J Obstet Gynecol 1967;99:86-90. doi:10.1016/S0002-9378(16)34494-5

33 Pfizer. Depo-Provera Contraceptive Injection (medroxyprogesterone acetate) [package insert]. US Food and Drug Administration. 2010.

34 Lewis RA, Taylor D, Natavio MF, Melamed A, Felix J, Mishell DJr. Effects of the levonorgestrel-releasing intrauterine system on cervical mucus quality and sperm penetrability. Contraception 2010;82:491-6. doi:10.1016/j.contraception.2010.06.006

35 Andersson K, Batar I, Rybo G. Return to fertility after removal of a levonorgestrel-releasing intrauterine device and Nova-T. Contraception 1992;46:575-84. doi:10.1016/00107824(92)90122-A

36 Wesselink AK, Wise LA, Hatch EE, et al. Menstrual cycle characteristics and fecundability in a North American preconception cohort. Ann Epidemiol 2016;26:482-487.e1. doi:10.1016/j. annepidem.2016.05.006

37 Hatch EE, Hahn KA, Wise LA, et al. Evaluation of selection bias in an internet-based study of pregnancy planners. Epidemiology 2016;27:98-104. doi:10.1097/ EDE.0000000000000400

Web appendix: Supplementary material 